\title{
BUSINESS INTELLIGENCE MODELLING FOR GRADUATE ENTREPRENEUR PROGRAMME
}

\author{
${ }^{1}$ Muhamad Shahbani Abu Bakar \& ${ }^{2}$ Azman Ta'a \\ ${ }^{1,2}$ School of Computing, Universiti Utara Malaysia, Malaysia
}

shahbani@uum.edu.my; azman@uum.edu.my

\begin{abstract}
Business Intelligence (BI), which is the process of collecting, analysing, and transforming data using Data Warehouse (DW) is seen as one of the growing approaches to provide meaningful information for the Malaysian Ministry of Higher Education (MOHE). MOHE is responsible for managing various activities to encourage graduate entrepreneurs to venture into businesses and ensure that the country has many successful entrepreneurs. Therefore, systematic and accurate information needs to be available for planning, implementing, and monitoring entrepreneurs' performances. This paper proposes the modelling and designing of the graduate entrepreneur profile system Intelligent Profile Analysis Graduate Entrepreneur (iPAGE) using the BI approach. Two main methodologies were used, namely the Requirements Centric Operational Data Store (ReCODS) and the Rapid Application Development (RAD) to model and design this system. The iPAGE was validated and evaluated by users, entrepreneurs' personnel and DW experts. Indeed, the approach will be used to benchmark the development of an entrepreneurial information system in the future.
\end{abstract}

Keywords: Graduate entrepreneur, business intelligence, data warehouse, operational data store, rapid application development.

\section{INTRODUCTION}

The Malaysian Ministry of Higher Education (MOHE) requires quality information to evaluate the performance of organizations, understand the needs of customers and competitors, and expedite decision-making within the ministry. The use of information technology is seen as an advantage for 
MOHE to manage the information by developing various application systems to support the operations of the businesses. As a result of that, numerous application systems have been developed to facilitate MOHE in managing the large amounts of data and the wealth of information in organizations. These data which are often processed using various applications, undergo multiple stages and are stored in different departments. As a result, the management often finds it difficult and problematic to acquire accurate information for decision-making within the organization (Mohanty, 2006; Rainer, Turban, \& Porter, 2007). One of the crucial information required by MOHE currently is data related to graduate entrepreneurs in Institutions of Higher Learning (IHLs).

MOHE has set a target for students in IHLs to excel academically and become successful and knowledgeable entrepreneurs after they graduate. It is vital that entrepreneurs are knowledgeable, possess managerial skills and are able to plan and manage their businesses in this increasingly complex and competitive business world. Over the years, MOHE has set up entrepreneurial units, committees, councils and cooperation among universities to conduct entrepreneur culture programmes such as the Graduate Entrepreneurship Programme (GEP) and the Student in Free Enterprise (SIFE) programme. MOHE however, does not possess the complete entrepreneurs' profiles that can be used for analysis and manifest the success of these entrepreneur programmes. In addition, MOHE must monitor the entrepreneurial units in more than 20 universities that have different organizational structure, scope and entrepreneurship programmes.

Based on these objectives, each university has a responsibility to nurture knowledgeable graduate entrepreneurs and become the point of reference for entrepreneurial programmes. To achieve these objectives, correct and accurate information is needed to implement and evaluate the achievement of the entrepreneur programmes. In this case, a systematic development of an information system is necessary in order to examine the effectiveness of the entrepreneurial programmes, particularly the achievement of graduate entrepreneurs. The required information includes the entrepreneur's profile, academic qualifications, business profile, training and business funding sources, and opportunities. This information is then integrated to obtain a complete profile of the entrepreneur. This article aims to present the development process of the Intelligent Profile Analysis Graduate Entrepreneur (iPAGE) system by using the Business Intelligence (BI) approach, which comprises the Requirements Centric Operational Data Store (ReCODS) and the Rapid Application Development (RAD) methodologies. 


\section{INFORMATION MANAGEMENT IN ORGANIZATIONS}

This study focused on modelling and designing the iPAGE application using the Operational Data Store (ODS) in the BI approach. The subject area of this study was the profile analysis conducted by MOHE to manage graduate entrepreneurs. In the following section, information management activities, based on the theory of information processing in organizations, BI, the ODS' role and graduate entrepreneurs' profiles are discussed.

\section{Information Processing}

The General System Theory (GST), the Organizational Information Processing Theory (OIPT) and the Knowledge Based Theory of the Firm (KBTF) were used as the basis of this study with the aim to understand the relationship between an organization, its information processing activities, and the importance of information and knowledge within the said organization. This research was conducted based on these theories and considers all the entities that exist in an organization's resource information system environment, taking into account both the internal and the external data sources. Environmental conditions and methods for connecting these system entities need to be carefully considered to ensure the developed system runs smoothly and achieves the organizational goals. ODS, Data Warehouse (DW) and BI technology are innovative solutions that facilitate this complex process and aid the OIPT to create and disseminate information within an organization.

GST was proposed by a biologist, Ludwig von Bertalanffy in 1936, referring to the human body as a metaphor to explain this theory. The basis of this theory emphasizes the interrelationship and interdependence between the parts that are inherent in an entity that was formed into a system and functions as a whole. It focuses on how the entities in a system relate and interact. The use of GST is very significant to the management of organizations to generate meaningful information in today's business environment. In today's complex business environment, organizations face an arduous task in managing its information. Data is usually stored scattered in various locations, running on various hardware and software platforms. Worse, some data is not integrated and keeping up with the ever-changing Information Technology (IT) policies due to rapid changes in the IT world is not easy. This situation reflects that the entities that exist within the organization are separated, suggests that the separated entities should be integrated and linked to obtain the information as required. 
To understand the management of information within the organization, the OIPT theory is applied. The OIPT theory was proposed by Galbraith (1973) which emphasizes on three key concepts in the management of organizational information: the needs to process information; the ability to process information; and a combination of need and ability to process information in order to achieve optimal use of information. The theory states that the organization needs quality information to manage uncertainties within the complex and the dynamic organizational environment, and the need to improve methods to make the right decisions in the organization. Uncertain information environment refers to the rapid changes of policies which customers find difficult to understand and the rapid advances in information technology innovation. Figure 1 shows an overview of information management within the organization based on the OIPT.

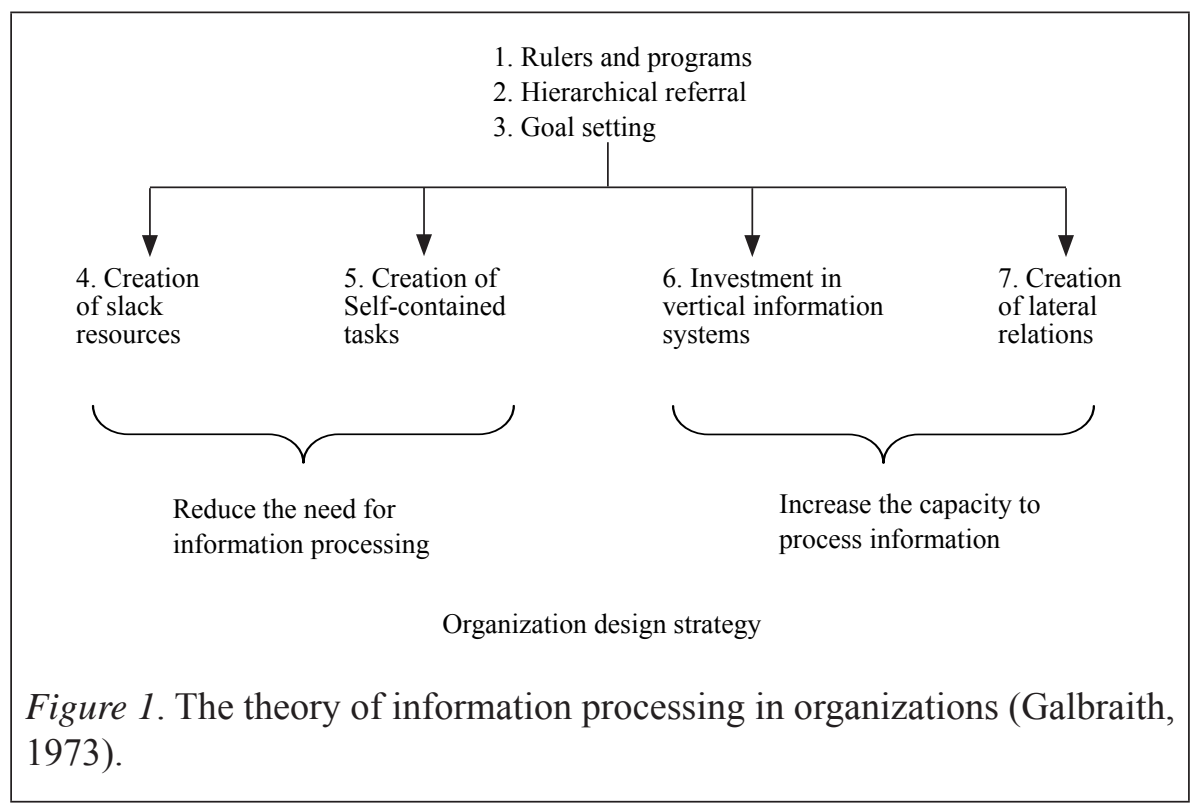

The theory also discusses the innovation of information technology to process data in order to obtain different information in the organization. Bento and Bento (2005) in their study based on OIPT identified three achievements (outcomes) that can be derived from the System Performance Management which are quality of information, effectiveness and usefulness of the system for management decision-making within the organization. They also stated that the organization's needs, management capacity and technological capabilities need to be blended with the organization to get quality information for management decision making. The researchers also conducted a study and concluded that the OIPT plays an important role for information management 
and organizational performance, particularly in the field of operations management research (Tatikonda \& Rosenthal, 2000). ODS, DW and BI are innovative technologies developed for complex information processing and support the OIPT to acquire quality information within the organization. Decision-makers use information management tools to translate data into information, and then transform the information into knowledge to facilitate decision-making and management of an organization. However, the overflow of data poses a challenge for organizations to extract strategic information. To produce quality information, the data must be processed before knowledge can be generated within the organization. The KBTF theory says the diversity of knowledge (heterogeneous knowledge) is the source of the most significant and strategic information in the organization (Barney, 1991). The diversity of knowledge involves various entities, including organizational culture, policies, work routines, documents, systems and employees that look set to increase the capacity of the organization. Information technology plays an important role in the KBTF in which information systems can contribute to organizationalknowledge creation through the information that can be synthesized, improve quality and assist in the understanding of knowledge-management within the organization (Grant, 1996). The KBTF theory can help researchers in this study as a reference to understand the knowledge to be built within the organization to develop the tactical and strategic information required in an organizational setting. This theory can also be used as a reference by researchers to understand the relationship between an organization's environment and the information needed to develop a data model for BI applications.

\section{Business Intelligence}

BI is an approach used by organizations today to get quality strategic information to predict the future trend. Gartner (2010) reported that in 2012 more than 35 per cent of the 5,000 large companies failed to make the right decisions related to business and marketing due to insufficient information. Within the same year, 40 per cent of the overall information technology budgets were invested in BI applications to obtain accurate business information. BI refers to the use of technology to collect and use information effectively for enhancing business effectiveness. Wu (2000) defined BI from the perspective of data analysis that "the process of gathering high quality and meaningful information about the subject matter being researched will help the individual(s) analyse the information, draw conclusions or make assumptions". Imhoff, Galemmo and Geiger (2003) mentioned BI as a process to convert data into meaningful information and knowledge to determine the current situation, make decisions and predict the circumstances that will occur in the future of the organization. 
There are also researchers who assert that BI is associated with decisionmaking (Olszak \& Zemba, 2006; Gibson, Arnott \& Jagielska, 2004; Negash Gray, 2003; Imhoff et al., 2003). Based on these definitions, BI is generally a business management term which refers to applications and technologies used to collect, parse, analyse and present quality and strategic information for the operation of an organization. The basic concept is to take BI operational data from various sources, clean these data, convert them into DW and then organize the data by using BI tools in order to get strategic information within the organization. Imhoff et al. (2003) proposed that the Corporate Information Factory (CIF) be used to support decision-making in a business environment. CIF architecture combines five major databases, namely the operation data, DW, ODS, Data Mart (DM) and the operation mart where the data are effectively integrated by a process that takes data from various data sources in a business environment and then distributes to business users.

Many studies discussed the implementation of BI applications in the organization. BI applications provide a benefit to the organization, especially to the management teams involved in making decisions such as the control manager, account manager, sales manager and the board member of an organization (Rasmussen, Goldy, \& Solli, 2002). The organizations' sectors typically which use BI applications are trading, banking and finance, insurance, telecommunications, and manufacturing (Reinschmidt \& Francoise, 2000).

Other studies also discussed the implementation of BI applications in the organization. In the health sector, BI was integrated into the objectives of an organization, and information technology components as a healthcare management model. Broadbent and Weill (1993) used IT in the banking sector to harmonize business strategy and information strategy so that banks could compete competitively. IBM has successfully conducted a number of BI projects, especially in the areas of supply of utilities such as electricity, gas and water sectors for strategic information on decision-making (Erickson, 2005). Within the same sectors, Rofail (2005) also shared their success by claiming that the right information from BI had been used to make decisions on the Water and Power Supply Company in Los Angeles, USA. Gibson et al. (2004) in their study said that BI provided significant business value by improving the effectiveness of management decision-making. Their review also found that the BI technology had benefits that cannot be seen (intangible benefits) by suggesting several ways to measure the effectiveness of the BI. Mannino (2007) also said BI applications were developed for achieving strategic business information and making the organization more competitive. He added that BI applications would help to find new markets, focus on profitable customers, understand customer requirements and reduce inventory costs. 


\section{Operational Data Store}

Inmon (1999) defined the ODS as "an architectural construct that is subjectoriented, integrated, volatile, current valued, and contains only corporate detailed data". In a different view of system development, Baragoin, Marini, Morgan, Meller, Perkins and Yim (2001) stated ODS as "an environment where data from a different operational database is integrated". Many researchers have included ODS in operational data integration to provide integrated information to the user community within the organization. Kimball and Ross (2002) also said the ODS is a data component that can be positioned along the DW-system development. The approach that combines the ODS and DW technology have successfully provided a BI environment to support strategic and tactical information within an organization. According to them, the ODS has a data capacity, which is frequently updated and integrated with operational data. Imhoff et al. (2003) added that the ODS is used to make tactical decisions as compared with the DW which is used to support strategic decisions. Figure 2 shows the characteristics of ODS and the relationship between operational data and information for decision-making. Figure 3 illustrates that the general architecture of ODS consists of data sources, data acquisition, and enterprise data layer.

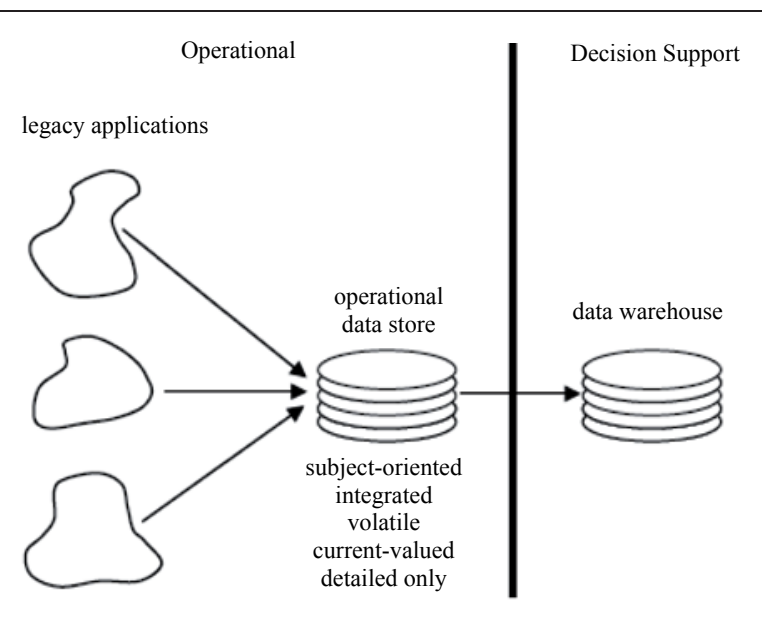

Figure 2. Characteristics of ODS.

Using ODS components in the DW architecture is a good approach to obtain information across borders that organize the business function data from multiple applications into one subject area (Baragoin et al., 2001). ODS not only serves as data storage, but also serves as a component that provides facilities to integrate, process and present data in subject areas assigned to 
user communities within the organization. Baragoin et al. (2001) says there are some advantages from the use of ODS in BI applications. Among them is that ODS provides access to critical data in the operational data, capable of achieving and presenting information in real time, capable of generating better operational reports from the transaction system and reducing time to implement the DW system because some data in the ODS can be used in the DW. This view is supported by Date (2007) who said that ODS is a database of special ability to produce operational reports, support business operations, and consolidate data from different databases. It increases the storage space but is smaller than that of DW because it does not keep a history of transactions, and produces reports based on current data.

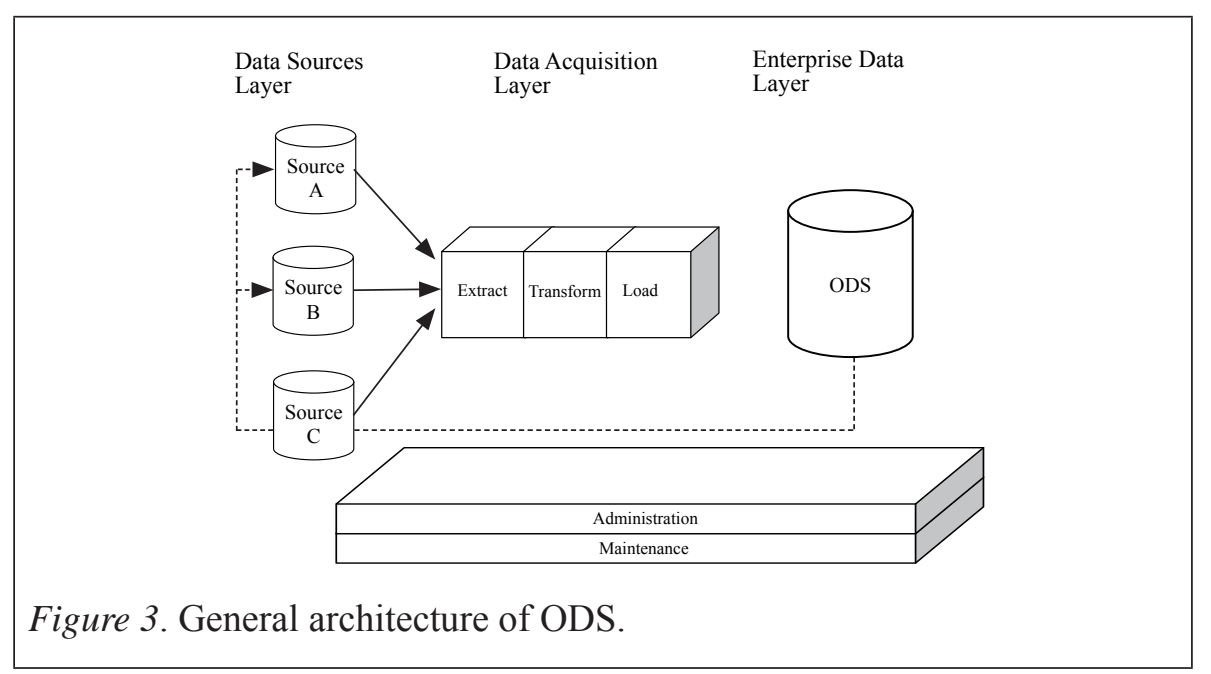

The approach they undertook was combining the ODS and DW technology to create information in the BI environment to support strategic and tactical information in the organization. In this case, the ODS' role is that it organizes operational data from various databases that are integrated to present current information. On the other hand, DW supports strategic information transaction history. The ODS also provides information to the DW by transferring the information in batches and at the same time ODS can organize its own information. In general, the ODS and DW have their own roles in the BI environment in which both components can provide quality information to the organization.

ODS is a component that links operational data and the DW in the BI architecture. The technology required to support the ODS for managing data is divided into three main components, namely the transfer data software, middleware and server environment ODS (Inmon, 1999). Data transformation 
software is used to transfer and manipulate data from the operational stage into the ODS. Meanwhile, the role of the middleware is to link the database applications and, in some cases, it serves as a liaison between the ODS and DW. The ODS platform is a server computing environment capable of managing the operating system to support Online Transactional Processing (OLTP) such as updating data, managing data online, managing the query language and functions in a computer network environment. Moreover, the ODS architecture is built to process data before tactical or current reports are generated and disseminated to the DW.

Baragoin et al. (2001) stated that the ODS architecture can be divided into three layers: namely: (a) data source layer; (b) data acquisition layer; and (c) enterprise data layer. The data source layer will manipulate the data operations, and the various external sources can be integrated into the architecture of the ODS. The Layer for the data source will take the data from the data source, gather and transfer that data into a format that is determined by the ODS. The enterprise data layer is the data targets that are built into a database. This layer builds on the administration and maintenance requirements for all the three levels of the ODS architecture. However, Inmon (2000) has classified ODS into four different classes (i.e. class I, class II, class III, and class IV) to speed up the transformation of data into the ODS.

Inmon (1999) explained that understanding the ODS architecture and the ODS-class design is important in the ODS database. The ODS database design depends on the ODS class requirement analysis. This research focused on the ODS approach in modelling and designing the BI system for graduate entrepreneurs in IHL.

\section{Graduate Entrepreneurship}

A graduate entrepreneur is an entrepreneur who plans, manages and develops an individual business or a group in the context of the entrepreneurship university programme (Kirby, 1992). Entrepreneur refers to two categories: Graduate entrepreneur and siswaniaga entrepreneur. Siswaniaga entrepreneurs are university students who are still studying in a university, and who conduct business under the monitoring and supervision of the University's Entrepreneur Unit. The motivation of a graduate entrepreneur programme is to develop knowledgeable entrepreneurs who can support the economic as well as business culture among graduate students. Among the programmes organized by the government are the Graduate Entrepreneur Scheme (GES), the Graduate Entrepreneurs Fund (GEF), Student Entrepreneur Training (SET), the Student Entrepreneurial Programmes (SEP), and the Graduate Development Programme (GDP). 
The government also organizes courses to graduate entrepreneurs like SEP to further their knowledge of entrepreneurship. Among the SEP modules are entrepreneurship characteristics, entrepreneurial motivation, the process of identifying, evaluating and selecting business ideas, creativity and innovation in business, production and operations management, small and medium business management, marketing management, financial management and establishment of business goals (Filzah et al., 2009).

SEP is supported by the University Entrepreneur Unit and the University Student Entrepreneurship Council of Malaysia (MAKMUM) which was established to coordinate and monitor the implementation of the small business enterprises (SMEs) at university level. The implementation of the SMEs is intended to give early exposure to the students so that they can engage in business after graduation. The programme was designed and implemented by the government, which showed a high level of government commitment to encourage graduates to become successful entrepreneurs. For example, Universiti Utara Malaysia (UUM) has established the Coorperative and Entrepreneurship Development Institute (CEDI) to support and proactively develop the society through the involvement of entrepreneurs and graduates. CEDI has organized entrepreneurship activities through courses, training, workshops and seminars for UUM students. Based on the UUM experience, the graduate entrepreneurs data need to be integrated and compiled into a database prior to analysis in order to determine the strategies needed for planning. The information is also shared by the entrepreneurs as a reference to the community, particularly to promote products and services for entrepreneurs in large. The entrepreneurs would establish a network among themselves to cooperate and improve their business activities.

Besides government agencies, private entrepreneurs are encouraged to assist and further develop these graduate entrepreneurs. For example, the National Entrepreneur Corporation Limited (NECL) has launched the Pioneer Graduate programmes to provide exposure about the world of business and entrepreneurship to young graduates, and hopes to create about 400 new entrepreneurs by the end of 2010. Indeed, NECL received a RM50 million fund from the Second Economic Stimulus Package in 2010 to train young graduates, where RM30 million was allocated for the training of graduate entrepreneurs and the remaining RM20 million of the fund was allocated to help participants start businesses (The Star, 2010). In addition, the researchers have also proposed several models to be implemented in public IHLs to ensure the smooth running of entrepreneurship programmes. Among the proposed models is the Integrated Graduate Entrepreneur Development as shown in Figure 4. 


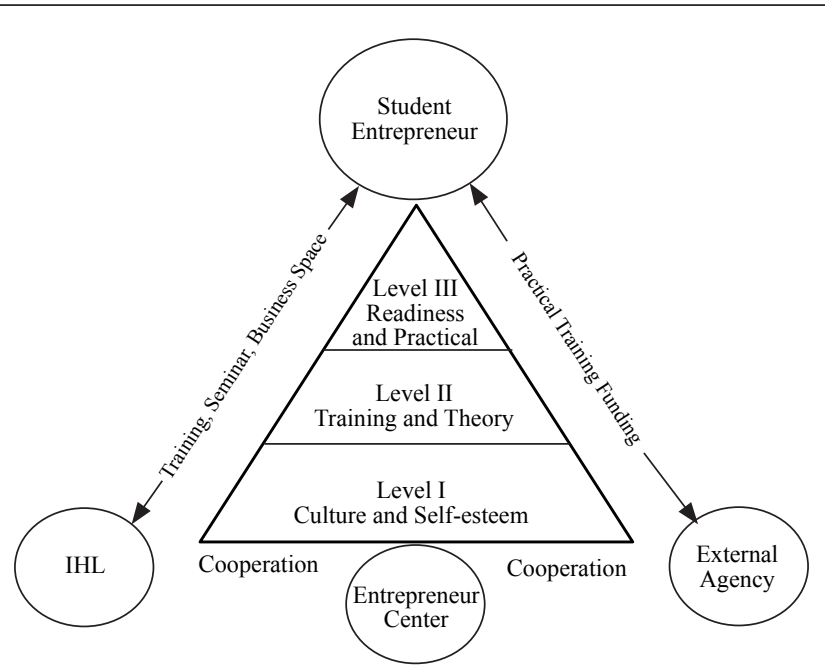

Figure 4. Graduate Entrepreneur Development Integration Model (Yahya, Mohd - Yusof \& Abu Bakar, 2009).

The above model aims to assist and guide the IHLs which do not have a strong entrepreneurship programme in their respective universities. The model is the result of the findings of the interpretive analysis conducted on the collected data and the results of the literature review made for this model that are related to entrepreneurship.

\section{Entrepreneurship Profile}

Development of a systematic profile for graduate entrepreneurs is a major challenge for the institutions that are responsible for managing the graduate entrepreneurs' information. The graduate business profile is a collection of personal information and information related to the entrepreneurs' businesses. IHLs usually manage the graduate entrepreneur activities using their own methods, and this is performed either manually or using a computer system. The information recorded in the graduate entrepreneur profiles includes the entrepreneur's personal information, academic qualification, business venture information, the training and entrepreneurship programmes, and funding sources. In addition, other information related to graduate entrepreneurs such as the business success story, awards won, the expertise possessed, and the creativity and innovation of the entrepreneurs are also recorded. Nevertheless, information about the failure of graduate entrepreneurs is also recorded from the studies conducted by academics. This information is systematically recorded to create a complete profile, and can be easily accessible and analysed by the end users. 
Through its Entrepreneurship Unit, MOHE is responsible for managing the entrepreneurship programme at 20 local public universities. Therefore, MOHE requires accurate business information to plan policies for the development of graduate entrepreneurships. Difficulties in obtaining accurate profiles of the graduate entrepreneurs would complicate the efforts to plan the entrepreneurship programmes (MOHE, 2010). Most of the graduate entrepreneur's information managed by the respective universities, whether in digital form, text, files or directories are based on the format specified by each university. Therefore, a big challenge for MOHE is to build a database for graduate entrepreneurs where entrepreneur profiles can be accessed quickly and accurately.

A graduate entrepreneur's profile needs a variety of information from various sources to be integrated to form an integrated database. The preceding discussion concluded that to develop a profile of the graduate entrepreneurs a variety of information such as personal information, academic qualification, business information, training information, and funding information is needed. The collection of information is based on various locations of the 20 public IHLs. The profiles of the graduate entrepreneurs can be used to predict future information for MOHE's strategic planning. The information located in different applications is integrated into a database for information analysis, and the use of appropriate hardware and software technologies is necessary to create this database. The theory of information processing in organizations, $\mathrm{BI}$, and ODS technologies are required and relevant in the development of graduate entrepreneur's database for managing the profiles of graduate entrepreneurs. This has been discussed carefully and has become a foundation for developing the iPAGE.

\section{ODS APPROACH FOR IPAGE}

The ODS data model in BI architecture is used to develop the iPAGE application. The ODS data model is capable of integrating data from heterogeneous data sources and structure that can facilitate the construction of the operational, tactical and analytical reporting. Thus, the analysis of requirements and development of the iPAGE applications requires a suitable model to ensure the objectives of BI applications are achieved. Two main methods are used: Requirement Analysis for Operational Data Store (ReCODS) to determine the needs of BI-based iPAGE applications and Rapid Application Development (RAD) that is used to design and develop the iPAGE system. 


\section{ReCODS Model}

The ReCODS model that focuses on the analysis requirements of BI uses the ODS data model to develop this iPAGE application. In this model, the requirement analysis is divided into two phases: Organization Level Requirements and ODS Level Requirements (Abu Bakar \& Shiratuddin, 2009). In each phase, the activities involve the requirement gathering process and analyzing information. The organizational level requirement phase begins by defining the business domain and ends with the requirement specification of the organization. Meanwhile, the ODS level requirement phases determine the subject areas and produce the ODS requirement specification. For requirement gathering, three orientation approaches were used: business-oriented, dataoriented and consumer-oriented.

This model suggests the process of obtaining requirements by using two methods. These two methods are performed manually or through online community collaboration. The manual collaboration method includes interview, observation, questionnaires and discussion. Meanwhile, the online collaboration method involves a web-based approach such as forums, chat, Facebook, blog and email.

In the organization requirement phase, understanding the entire information of the organization environment is necessary. This phase begins with understanding and analyzing the business domains in an organization and ending with the specification requirements of the organization. Understanding the information requirements is focusing on specific subject areas of the application system that was developed. This phase involves six activities such as determining the business domain, determining the project funding, determining the organization structure, gathering requirements at the organization level, determining requirements at the organization level and identifying the requirement specification at the organizational level.

In the ODS requirement phase, the collection and analysis requirements were focused on the subject areas that had been set from the previous phase. This phase involves five steps: determining the subject areas, gathering requirements of subject areas, analysing subject areas, determining the ODS operation and specifying the ODS requirement specifications. In this phase, requirement gathering and analyzing are more focused to develop the iPAGE applications. This phase involves five activities such as determining the subject area, gathering subject area requirements, subject area requirement analysis, ODS requirement process, and ODS requirement specification. In determining the subject area, the focus is to collect requirements in specific 
subject areas that are obtained from the dominant existing applications and other inputs such as knowledge experts, questionnaires, technical information and applications. These approaches were presented in the ReCODS model as shown in Figure 5.

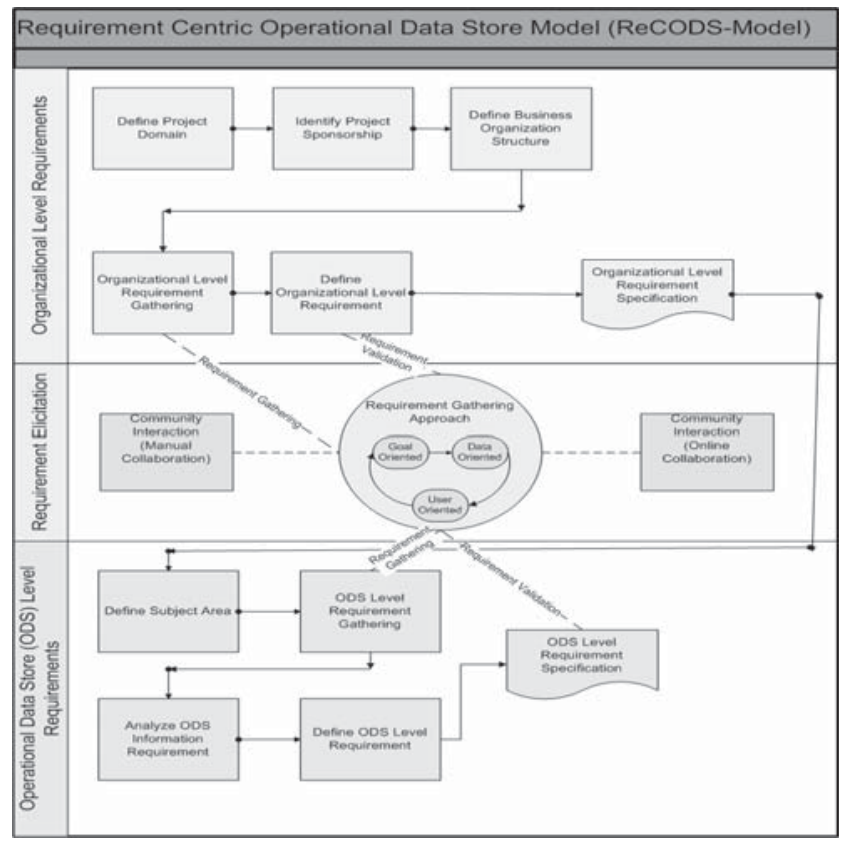

Figure 5. ReCODS model (Muhamad S. A. B. \& Norshuhada, 2009).

The ODS structure integrates BI information from various data sources, and develops a BI data model and thus is able to present information systematically. The ODS data structure is modelled by using the Entity Relationship (ER) model and dimensional (DM) model. The ODS data modelling requires several stages of the requirement process such as ODS integration, OD characteristics and ODS classification.

\section{ReCODS Architecture}

The ReCODS architecture describes the process of getting an overall requirement to develop the iPAGE applications that focuses on the structure of the ODS data as illustrated in Figure 6. This architecture begins by determining the parties involved in the iPAGE applications, such as MOHE, CEDI, MAKMUM, entrepreneurs, and developers. These parties interact 
manually, or through an online medium to exchange application requirements during the application-development period. In addition, this architecture also connects to the existing applications to be integrated into the structure of iPAGE data. Furthermore, the functions of extracting, transforming and loading (ETL) begins with data collection from various sources, transforming and loading data into the target data store (Taa, Abdullah, \& Norwawi, 2011). Clearly, the target data store is the ODS component. The updating of data sources from transaction systems should be coordinated with the data in the iPAGE application to ensure the information is accurate within the given time variance. The architecture focuses on the presentation of information in the form of a pyramid, which classifies the information into an operational, tactical and analytical report.

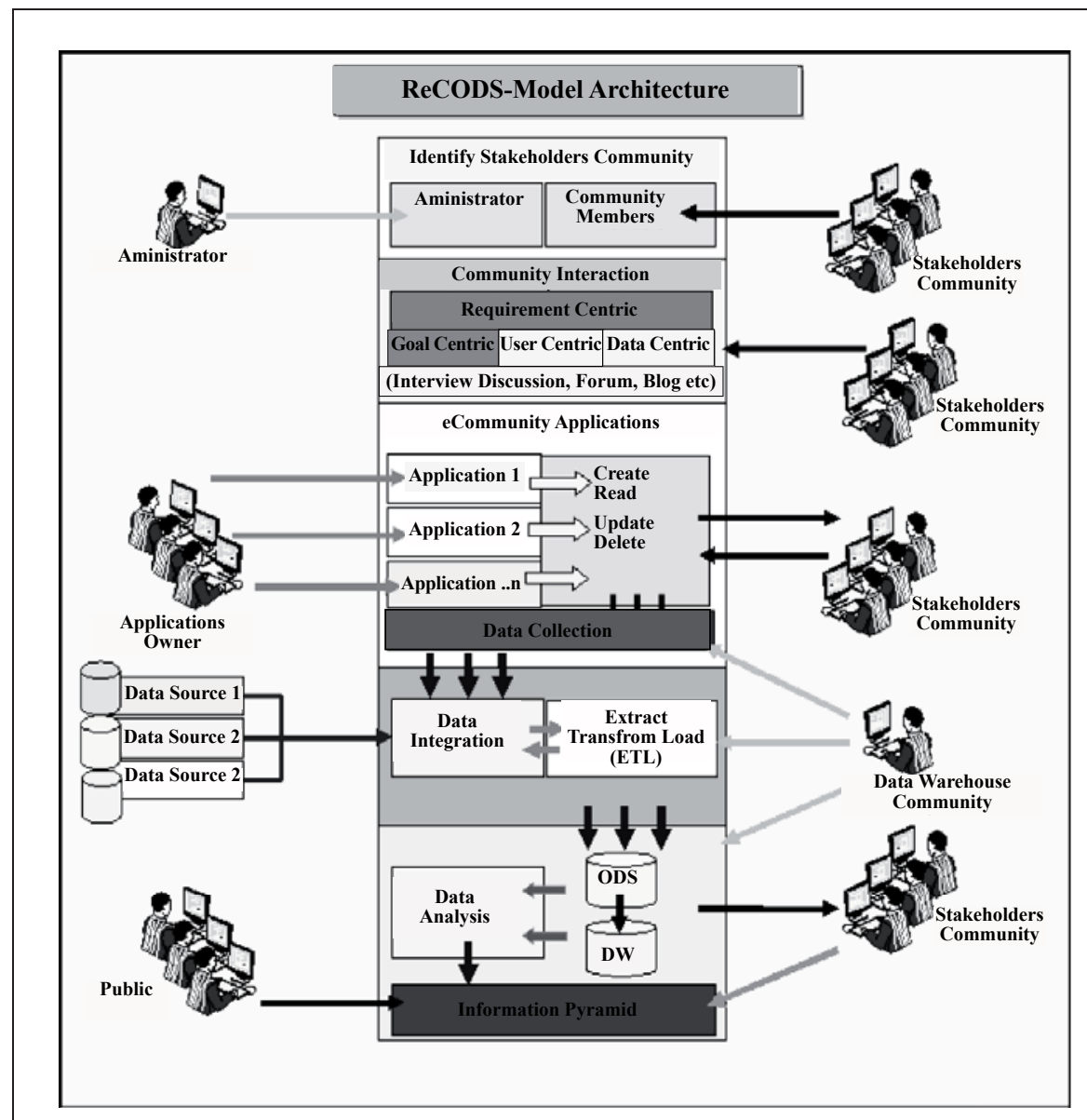

Figure 6. ReCODS architecture. 


\section{METHODOLOGY}

The methodology used to develop the iPAGE application is RAD. Generally, RAD is utilized to support the development of two main applications within iPAGE: Web Portal Entrepreneur Profile and Entrepreneur Profiles System. RAD was chosen to develop iPAGE because this methodology provides a systematic plan for the system development life cycle, which combines two techniques of evolutionary prototyping and development phases. These techniques are combined with the ReCODS model to support the need of BI components as depicted in Figure 7.

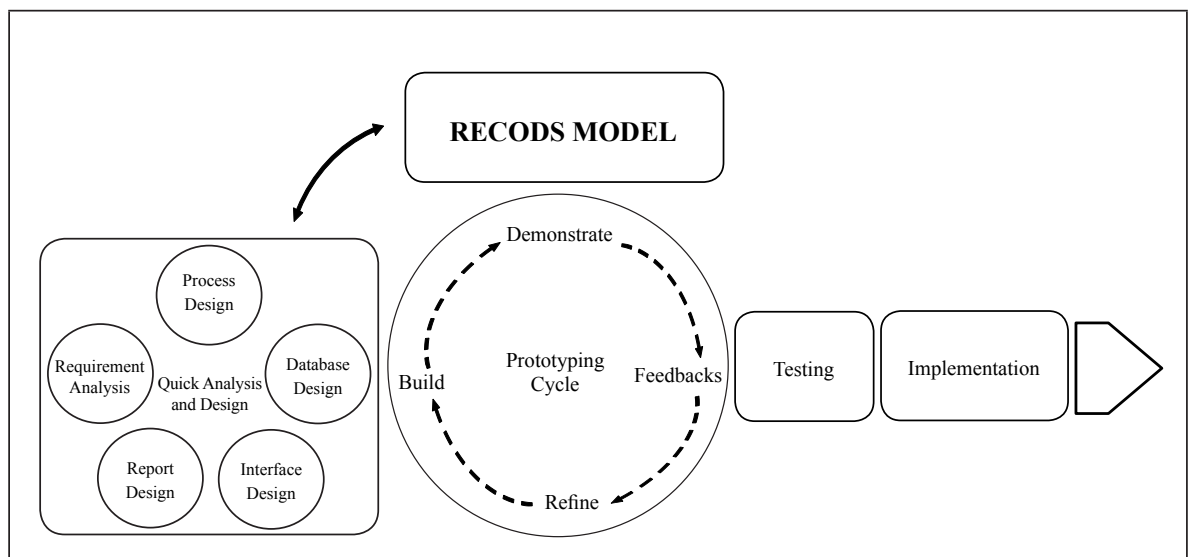

Figure 7. RAD methodology with ReCODS model.

In essence, the RAD methodology is divided into several stages, namely the planning and requirements analysis, prototype development, testing, and implementation of the system. In the planning and the analysis phase, the activities involved are requirements analysis, design process, database design, interface design and report design. After the analysis, the development phase was carried out. The web entrepreneur portal was developed during the development phase. In this phase, four main processes were carried out in iterations such as development, presentation, feedback and improvement. The prototype was improved gradually until it met the entire system requirements. The next phase was to test the application prototype to ensure the application was functioning properly and met the objectives of the system.

In summary, the ReCODS model that specialises in BI development methodology is combined with a RAD system that is known in agile software development methodology for developing the iPAGE. This research has 
utilized the advantages of RAD and the applicability of ReCODS for planning, modelling, designing, developing, testing, and implementing the iPAGE applications successfully.

\section{iPAGE - Web Entrepreneur Profile Development}

The iPage prototype, which was developed based on the ReCODS model is the main deliverable of this study. The prototype is based on the vertical prototype approach that provides functions for inserting and storing data in a database, and displays the data through screen inquiries and reports (Borysowich, 2007). iPAGE has two main system components that focus on different functions and roles to users: Web Entrepreneur Profile that contains functions for managing and accessing entrepreneur profiles, Portal Entrepreneur Profile, which acts as dispersal agents for entrepreneur information to entrepreneurs themselves, universities, MOHE, and the public.

\section{iPAGE - Requirement Analysis}

The design of the web entrepreneur profiles was conducted in steps: requirements analysis, process design, database design, interface design, and reports or query design. In the requirements analysis, the requirements were identified as entrepreneur profile, academic profile, fund profile, business profile, and entrepreneurship programme. A part of the detailed requirements analysis for the entrepreneur profile is shown in Table 1. Based on Table 1, the database was designed and developed to store and process the data for entrepreneur profile. However, the data types need to be analysed as a function, which only focuses on the functions of the web entrepreneur profiles.

\section{Process Design}

The process design begins with identifying the core processes of the web profile systems. The process is important to ensure that the data entered and updated by business process workflows are correct and carried out by valid actors (system users). The main actors (users) who communicate directly with this system are: (a) Entrepreneur Unit Manager - enter and update business data; (b) Entrepreneur Unit of IHL - prepare, review, update and verify business data; (c) Entrepreneur Unit of MOHE - access business information through a query or report; and (d) MAKMUM - access and verify the entrepreneur's information. In short, part of the design process is represented by the Use Case (UC) diagram model and is shown in Figure 8, Figure 9 and Figure 10. 


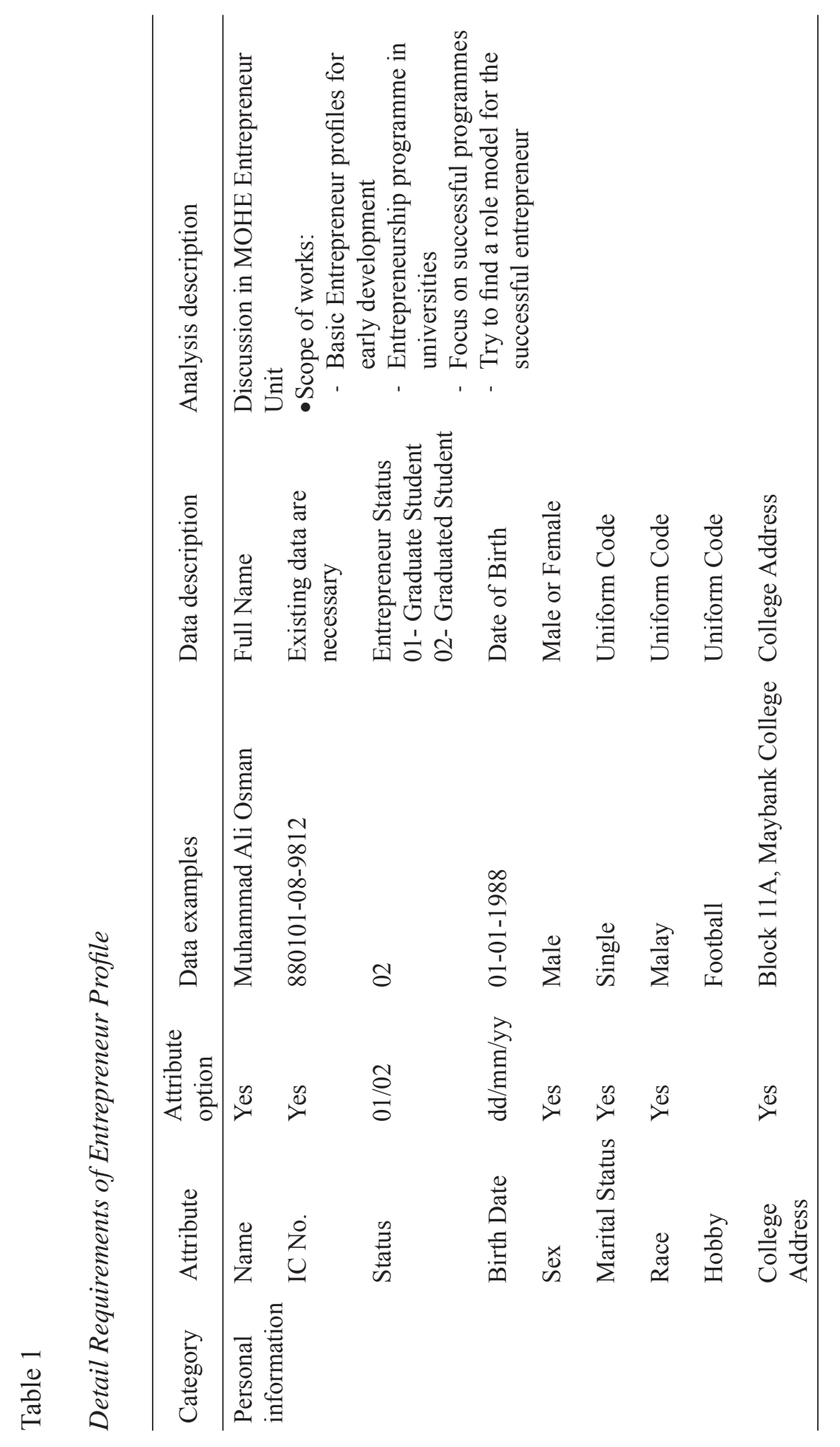




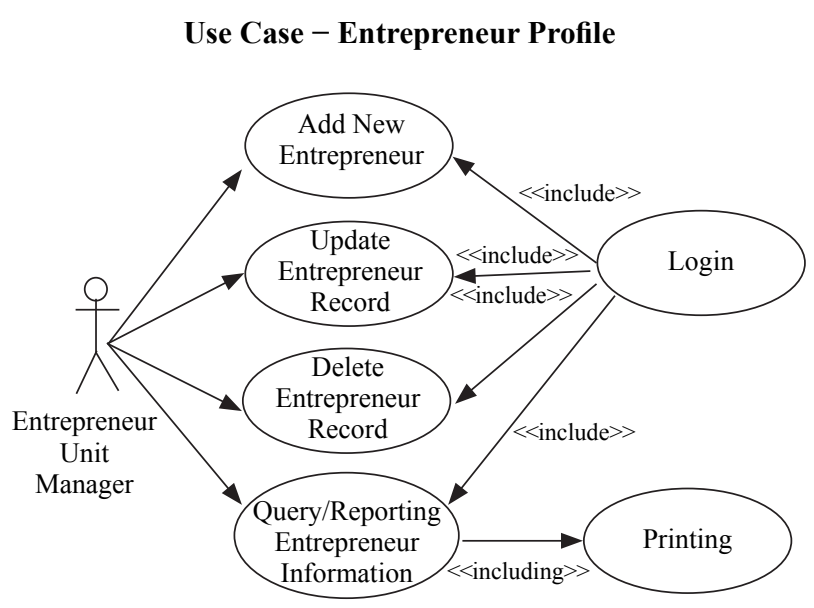

Figure 8. Main UC - entrepreneur profile.

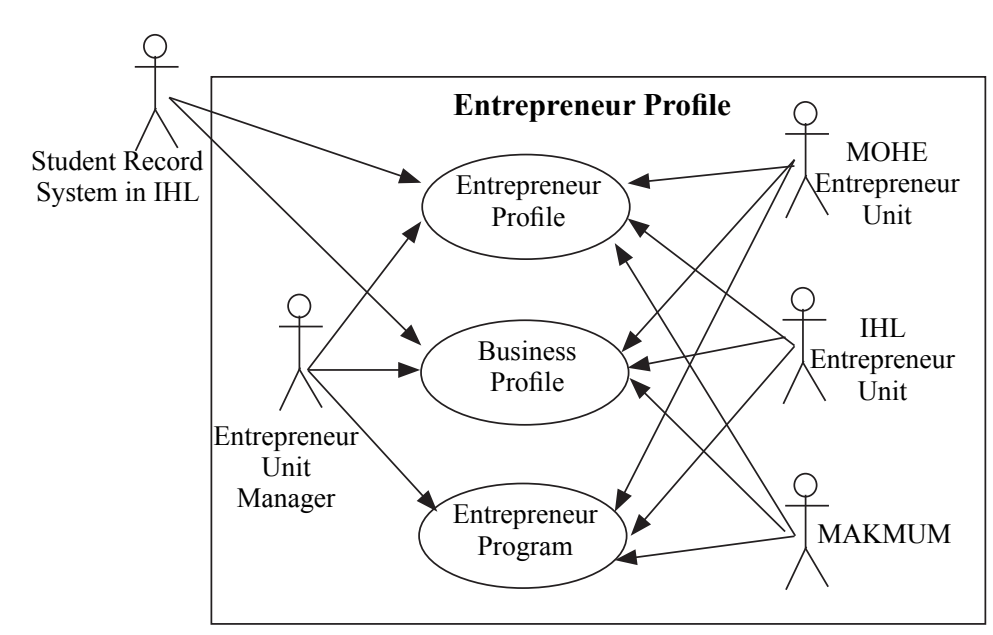

Figure 9. UC Level 1 - entrepreneur profile.

The process flow for each use case is represented by the activity diagram as shown in Figure 11. The activity diagram for inserting and verifying the entrepreneur profile data begins by reviewing the data received from the entrepreneurs of each university. This process is continued for all the requirements specified. The database design strategy is based on the attributes that exist for every entity from the requirements analysis and is represented by the class diagram model. 


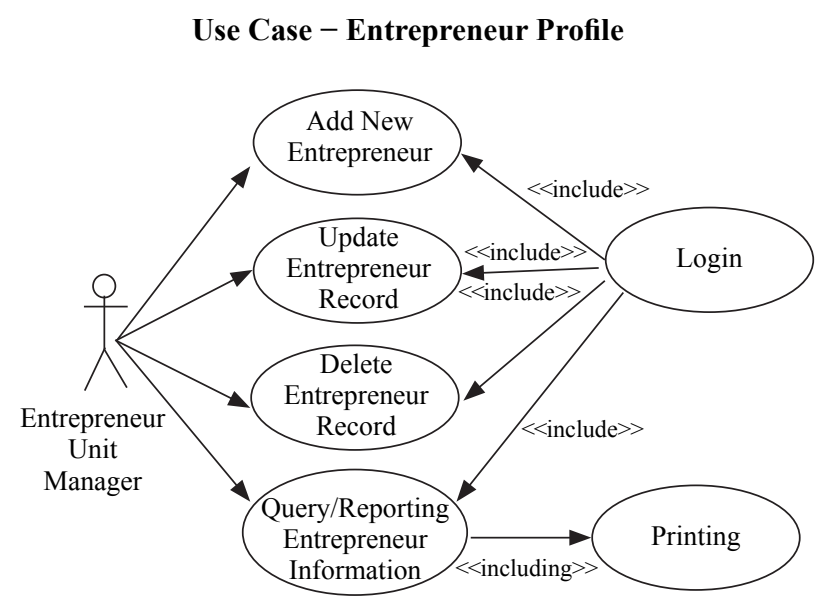

Figure 10. UC Level 1 - business profile.

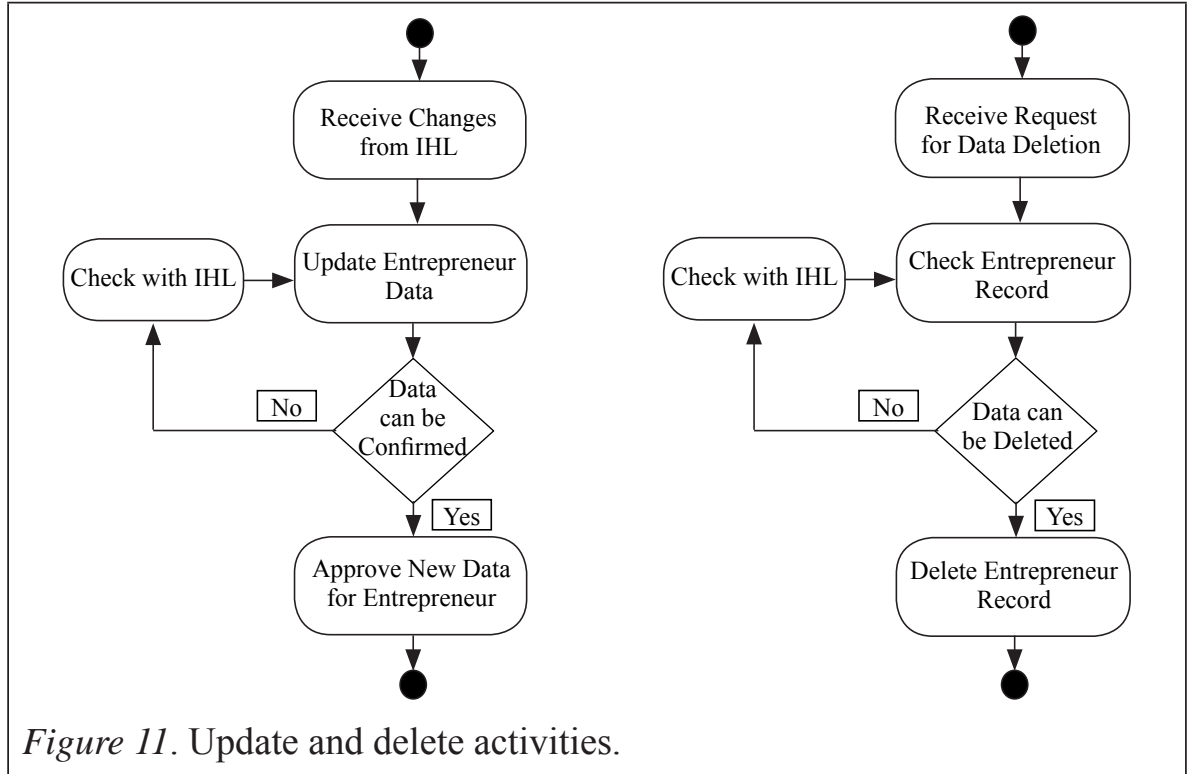

\section{Database Design}

Database design begins with identifying the entities, attributes and relationship with other entities. The representation of entities and their relationship is presented in a class diagram as shown in Figure 12. The data structures required to support entrepreneur profile information is needed by users, particularly MOHE and IHLs. The main entities are tbPersonal (personal data), tbAcademic 
(academic data), tbBusiness (business data), tbBusinessPerformance (business performance data), and tbCourse (entrepreneurship course data). Other supporting data are tbFund (business financing data), tbGstatus (business status), tbProgram (academic programmes), tbUniversity (IHL list), and tbState (states list). The design strategy is based on the attributes that exist for every entity generated from the requirements analysis. It is ready to be adjusted at any time according to the requirement changes. The relationship between entities was normalized to ensure the database design was in optimal condition.

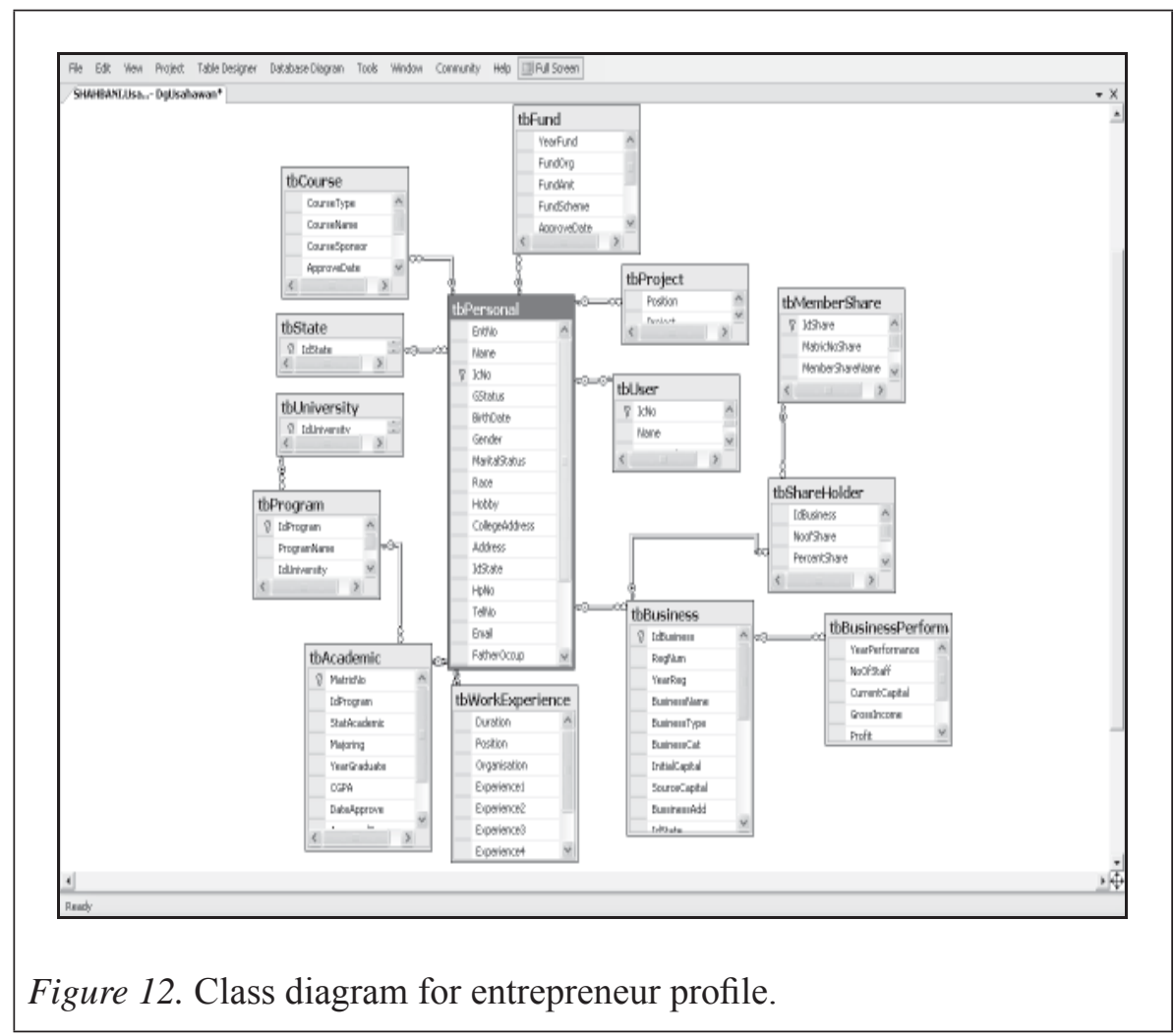

\section{Interface and Reporting Design}

The interface design is based on the process flow and data structures that support each transaction executed in the system. The interface design strategy classifies the design into four parts: (a) main/login interface; (b) basic data entry interface; (c) main data interface; and (d) checking and validation data interfaces. The reports vary according to user levels. The types of reports can be classified as operational, tactical and analysis. The main user, like 
MOHE, requires information that focuses on business statistics and analytics. Meanwhile, the management of the entrepreneur units in IHL needs more data on operational reports that are simple and concise. Examples of these design interfaces and reports are shown in Figure 13, Figure 14, Figure 15 and Figure 16.

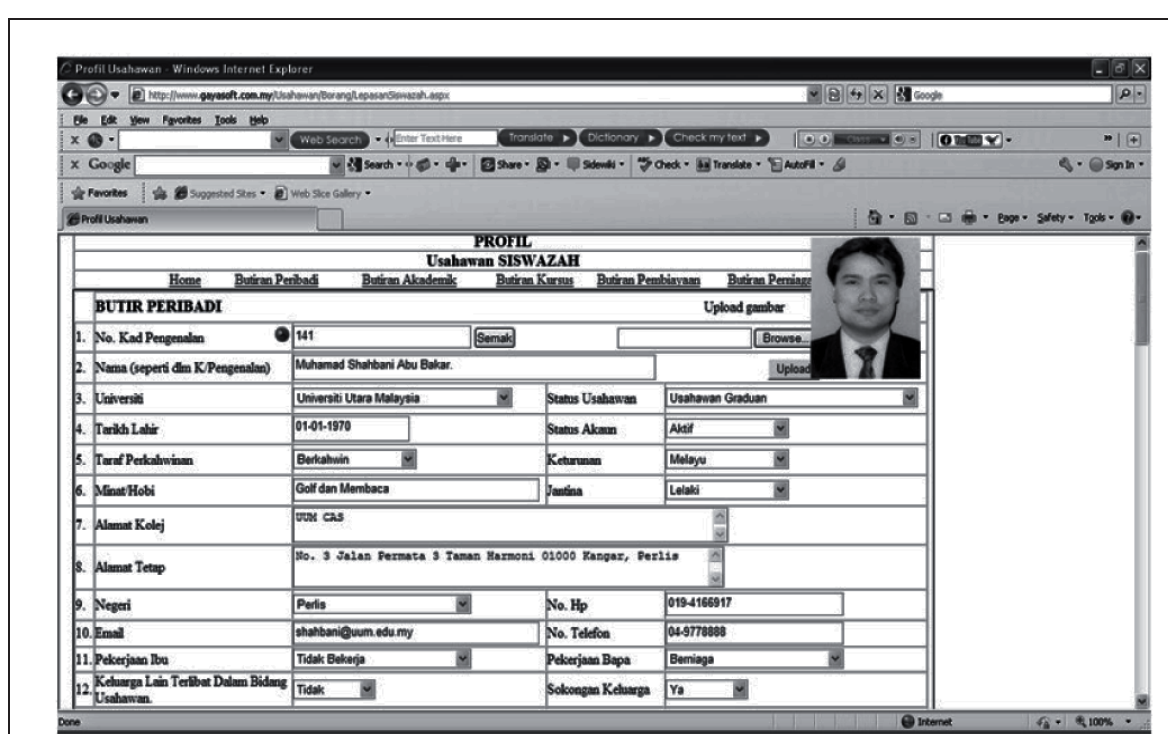

Figure 13. Main data entry - personal profile.

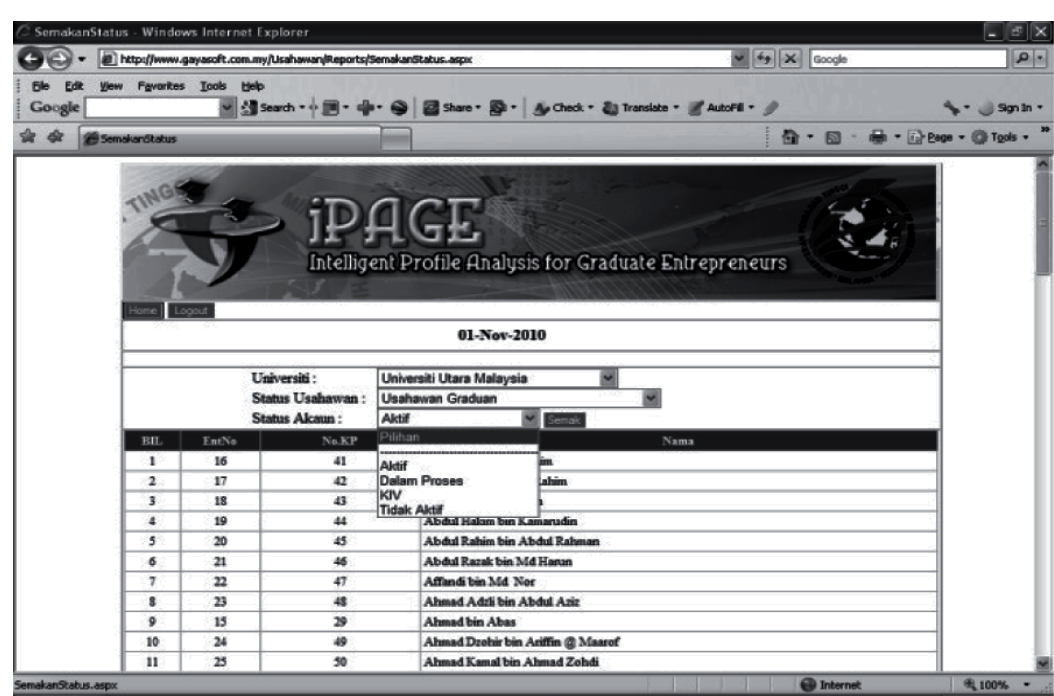

Figure 14. Checking and validation of data. 


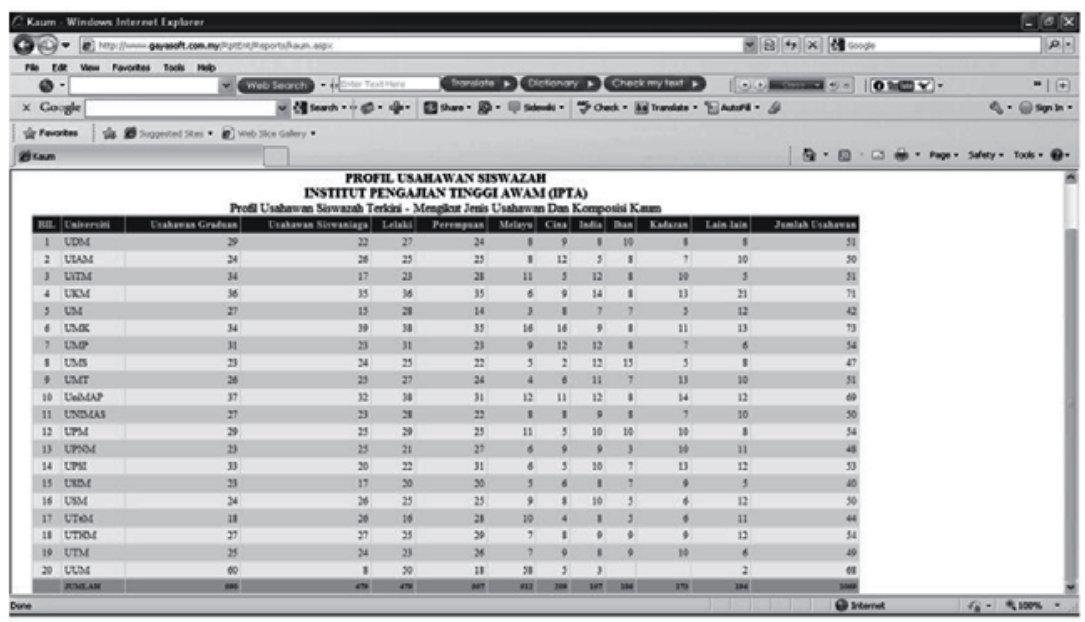

Figure 15. Entrepreneur statistics.

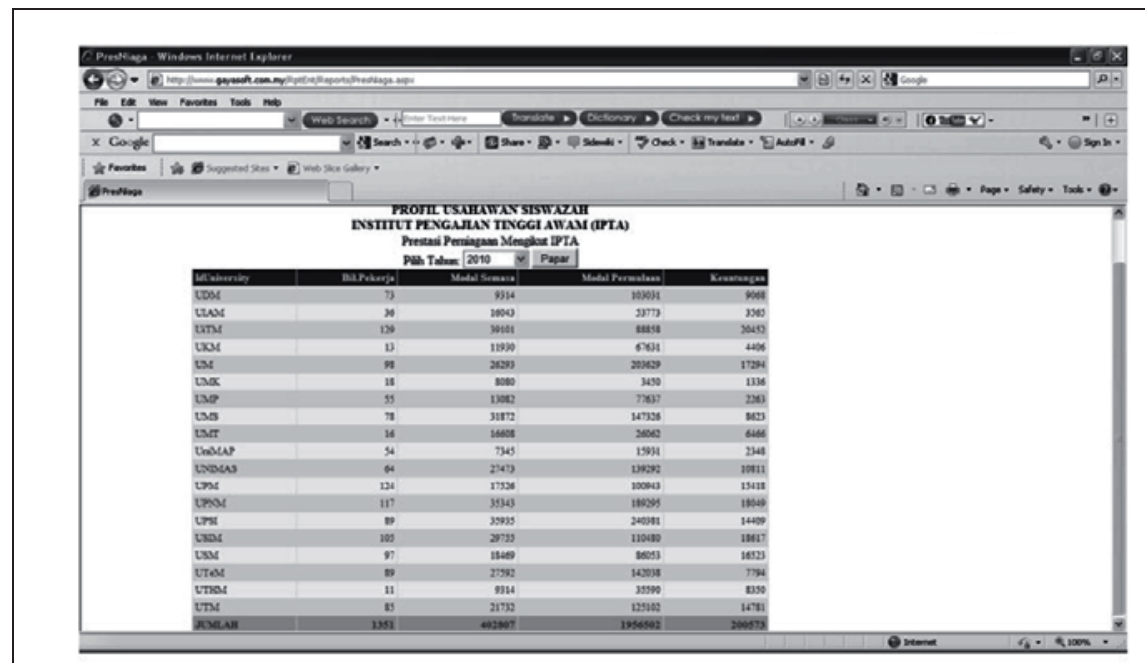

Figure 16. Business performance statistics.

\section{iPAGE - Portal Entrepreneur Profile}

The iPAGE application serves to disseminate entrepreneur's information in a format easily understood by users. The information presented is based on an entrepreneur's raw data that is processed and analysed using BI functionalities. The information is accessed through the portal personalization features and the latest security system. Importantly, the raw data are provided in dimensional modelling, which focuses on fact, dimension, and measure. To allow data 
sources available for the DW entrepreneurs, the important process, ETL, is implemented. The ETL process design is defined by using the Logical Data Map (LDM) method.

\section{Requirement Analysis}

The requirements for portal application are obtained from the main users of the system and several entrepreneur units of MOHE and IHLs. Several methods are adopted to get a complete requirement for the system such as interview, discussion, and document analysis. The requirements were analyzed according to ReCODS model, and parts of the results are shown in Table 2. Based on the classification of the information required by the user, the design of data warehousing and transformation operations (e.g. extract, merge, join, aggregation) of the relevant data sources was constructed accordingly.

Table 2

\section{Entrepreneur Profile Requirements}

\begin{tabular}{|c|c|c|}
\hline Classification & Required information & Users \\
\hline $\begin{array}{l}\text { Entrepreneur } \\
\text { programme }\end{array}$ & $\begin{array}{l}\text { - Number of university entrepreneurship programmes. } \\
\text { - Types of entrepreneurship programmes organized } \\
\text { by IHLs. } \\
\text { - The effectiveness of the graduates' entrepreneurship } \\
\text { - Enogramme. } \\
\text { - Strepreneur that can be a role model. } \\
\text { by the IHL against the type of business. }\end{array}$ & $\begin{array}{l}\text { MOHE } \\
\text { Entrepreneur Unit, } \\
\text { IHL Entrepreneur } \\
\text { Unit, MAKMUM }\end{array}$ \\
\hline $\begin{array}{l}\text { Entrepreneur } \\
\text { profile }\end{array}$ & $\begin{array}{l}\text { - Entrepreneurs profile by universities, programmes } \\
\text { of study, gender, race, state, and others. } \\
\text { - What are the entrepreneurs' success factors? } \\
\text { - Do successful entrepreneurs have a relationship } \\
\text { with type of business, etc. }\end{array}$ & $\begin{array}{l}\text { MOHE } \\
\text { Entrepreneur Unit, } \\
\text { IHL Entrepreneur } \\
\text { Unit, MAKMUM }\end{array}$ \\
\hline
\end{tabular}

\section{Data Warehouse Design}

The design of the entrepreneur data warehouse is constructed according to dimensional modelling (Kimball \& Ross, 2002). The dimensional model emphasizes data structures that focus on providing information to decisionmakers. Thus, the components of fact, dimensional, and measures are identified and addressed properly. Based on user requirements defined in Table 2, the data warehouse model for entrepreneurs is shown in Figure 17. 


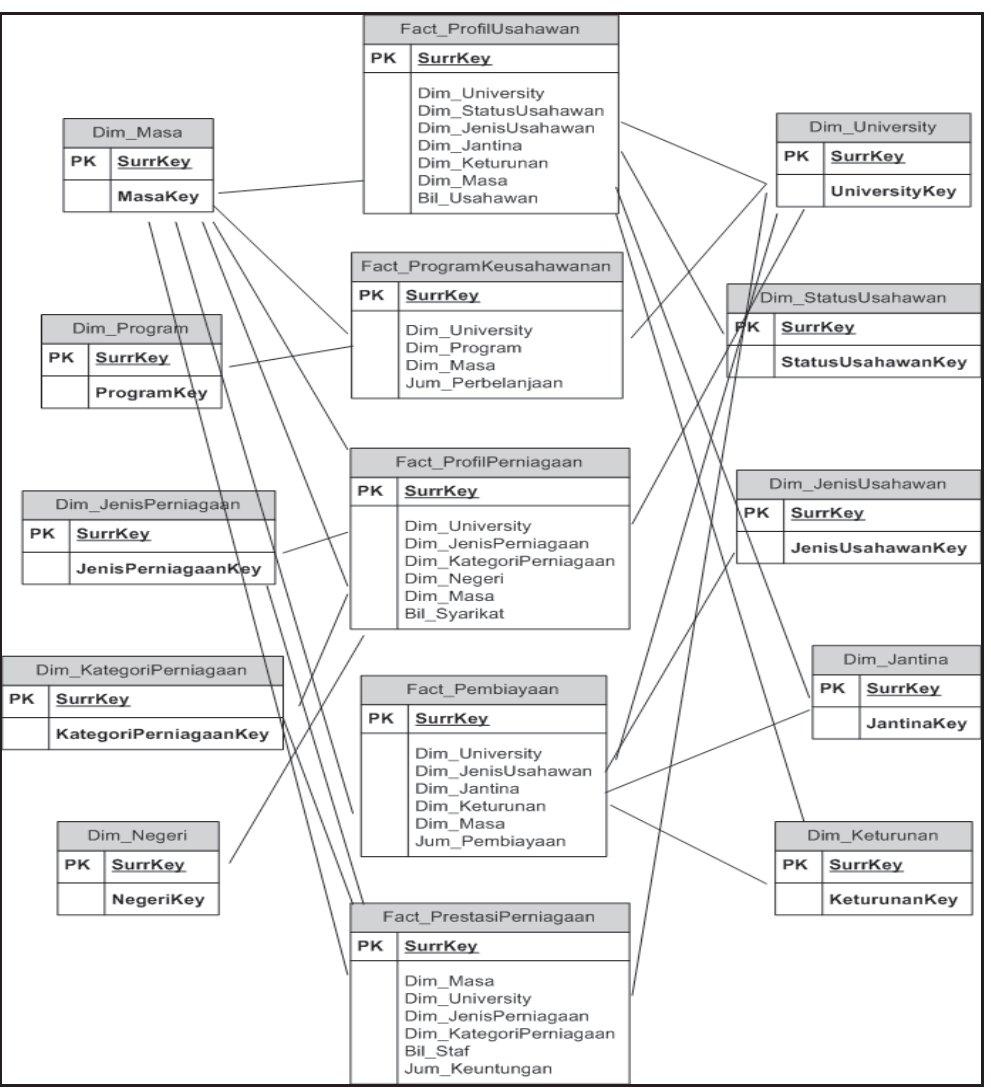

Figure 17. Dimensional model for entrepreneur profile.

\section{ETL Design}

The ETL allows raw data from data sources available to be transformed into the entrepreneur's data warehouse according to the ETL process design specification (Taa \& Norwawi, 2011). In general, the ETL process specification is defined in the Logical Data Map (LDM) (Kimball \& Caserta, 2004). The LDM records each activity in data processing, which contains information about data sources, target data, and transformation activities.

\section{Interface Design}

Interfaces are designed according to portal concepts, artificial intelligence and information or report required by users. The strategy is to classify the design into four divisions: (a) main interface / login; (b) ETL processes interface; (c) 
queries / reports interface; and (d) community / social interface. A part of the design is shown in Figure 18 and Figure 19.

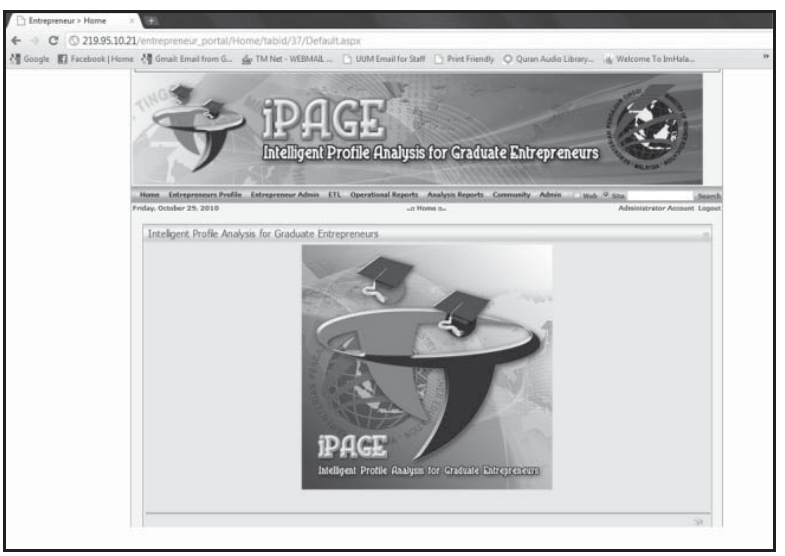

Figure 18. Main interface for portal.

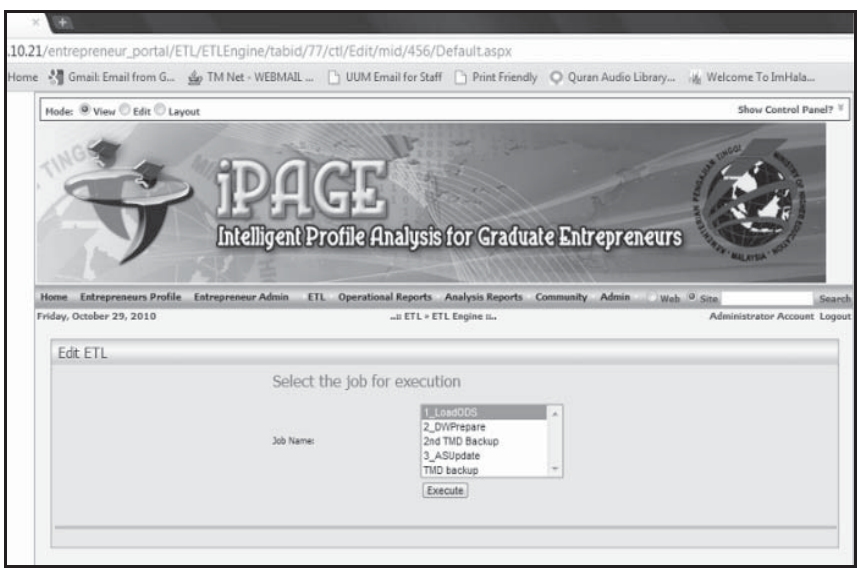

Figure 19. Main interface for ETL processes.

\section{Report Design}

The types of report in the portal can be classified as simple, detailed, statistics, and analysis. These reports are generated from the data warehouse architecture using BI functionalities. Examples of report design are shown in Figure 20 and Figure 21. 


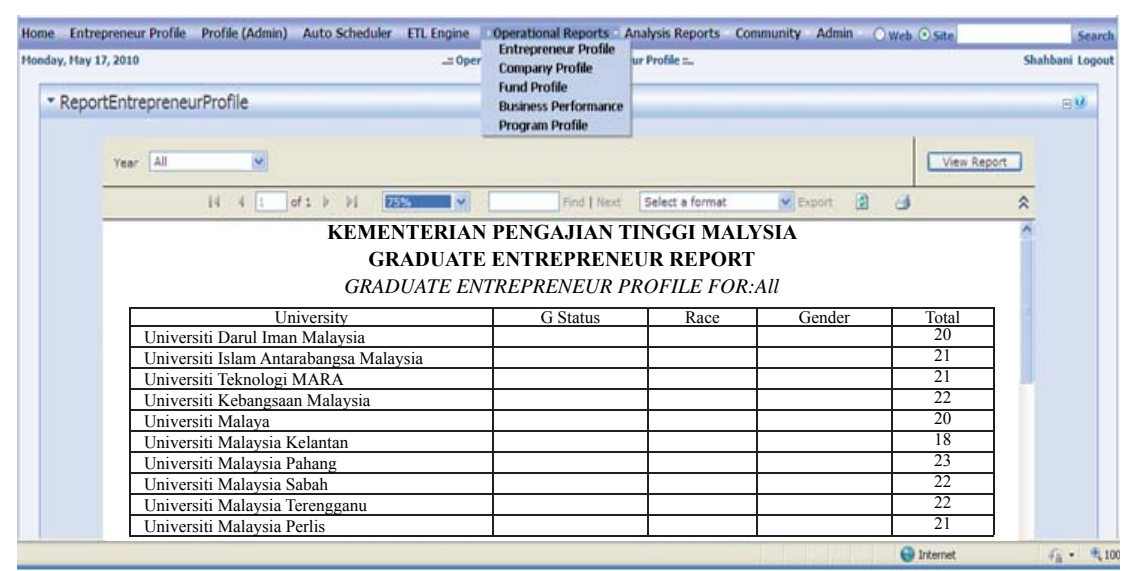

Figure 20. Entrepreneur profile reporting.

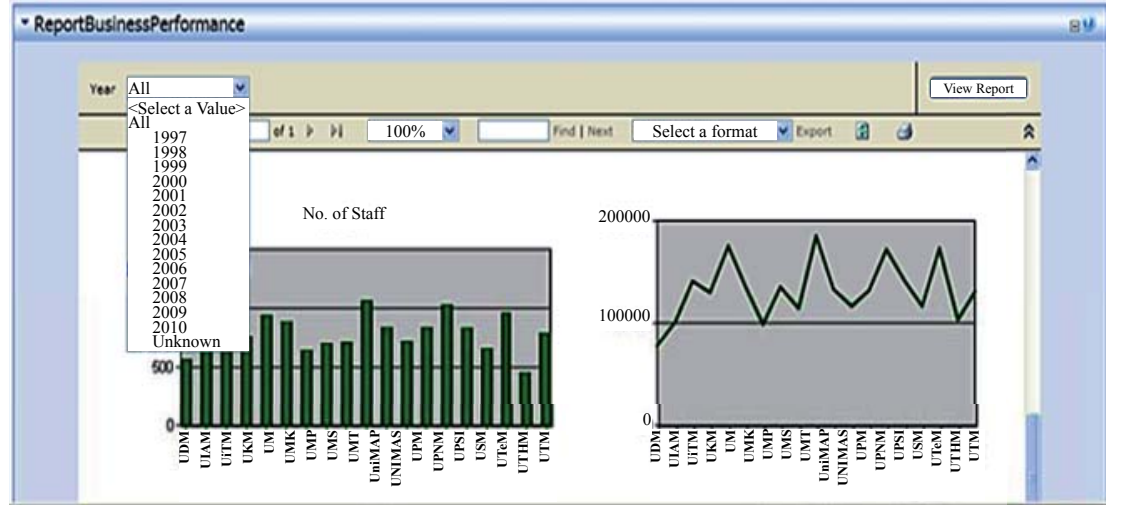

Figure 21. Business performance reporting.

\section{Implementation}

The implementation of iPAGE involves several organizations and people who organize the entrepreneurship programmes. The concept of physical architecture of the iPAGE implementation is shown in Figure 22. The website for the iPAGE - web entrepreneur profile can be accessed via the URL http:// www.gayasoft.com.my/entrepreneur_portal/ and the web entrepreneur portal profile can be accessed via the URL http://www.gayasoft.com.my/Usahawan/ Login.aspx. Both systems operate on a Windows server platform with 2 GB memory and 500 GB storage on the main hard disk. This application is 
developed using Microsoft Visual Studio, where the programme code is written in VB.Net and ASP.Net technologies. The database used is the Microsoft SQL Server Enterprise Edition and adopts the DotNetNuke as a portal engine. Login and password are manually provided by the system manager, who will determine whether the user is allowed access to the system. Currently, the system manager is the personnel of the IHL Entrepreneur Unit. The end users will be staffs from the entrepreneur unit in each public or private IHL. They participated in the implementation of this system organized by MOHE.

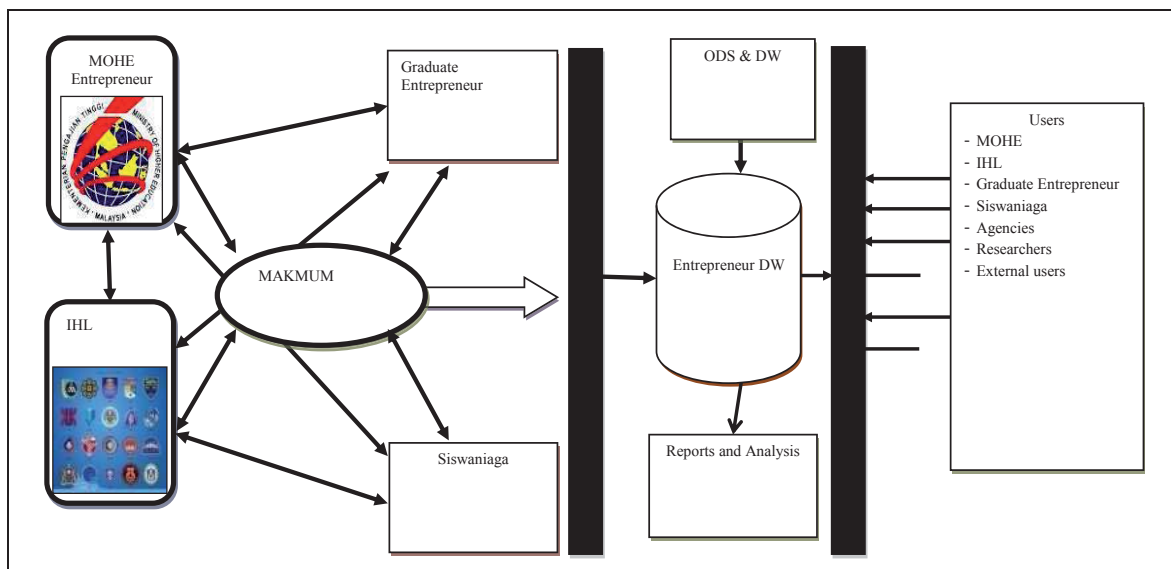

Figure 22. iPAGE implementation architecture.

\section{VALIDATION AND EVALUATION}

Formative testing was conducted to ensure the iPAGE functions were working properly, particularly in terms of usefulness, ease of use and meeting user requirements. In addition, the assessment of iPAGE was also made by involving the DW expert and the expert domain of entrepreneurship. A formative testing of iPAGE applications using questionnaires was adapted from Davis (1989), who suggested the components of Perceived Usefulness, Perceived Ease of Use, and User Acceptance of Information Technology. It was also an adaptation of the Technology Acceptance Model (Venkatesh \& Davis, 2000). The questionnaire was divided into two categories: (a) testing for usefulness; and (b) ease of use. There were 12 questions, and each question had a Likert scale from 1 (unlikely) to degree 5 (Likely). The feedback collected from the 32 respondents were analysed for each of the usability categories. The statistical results of the components of the usefulness and ease of use are shown in Table 3 and Figure 23. 
Table 3

Descriptive Statistics Results for iPAGE Application Testing

\begin{tabular}{lccc}
\hline Group & N & Mean & $\begin{array}{c}\text { Std. } \\
\text { Deviation }\end{array}$ \\
\hline Mean iPAGE & 32 & 4.375 & 0.54732 \\
Perceived Usefulness & 32 & 4.4375 & 0.53784 \\
Perceived Ease of Use & 32 & \\
\hline
\end{tabular}

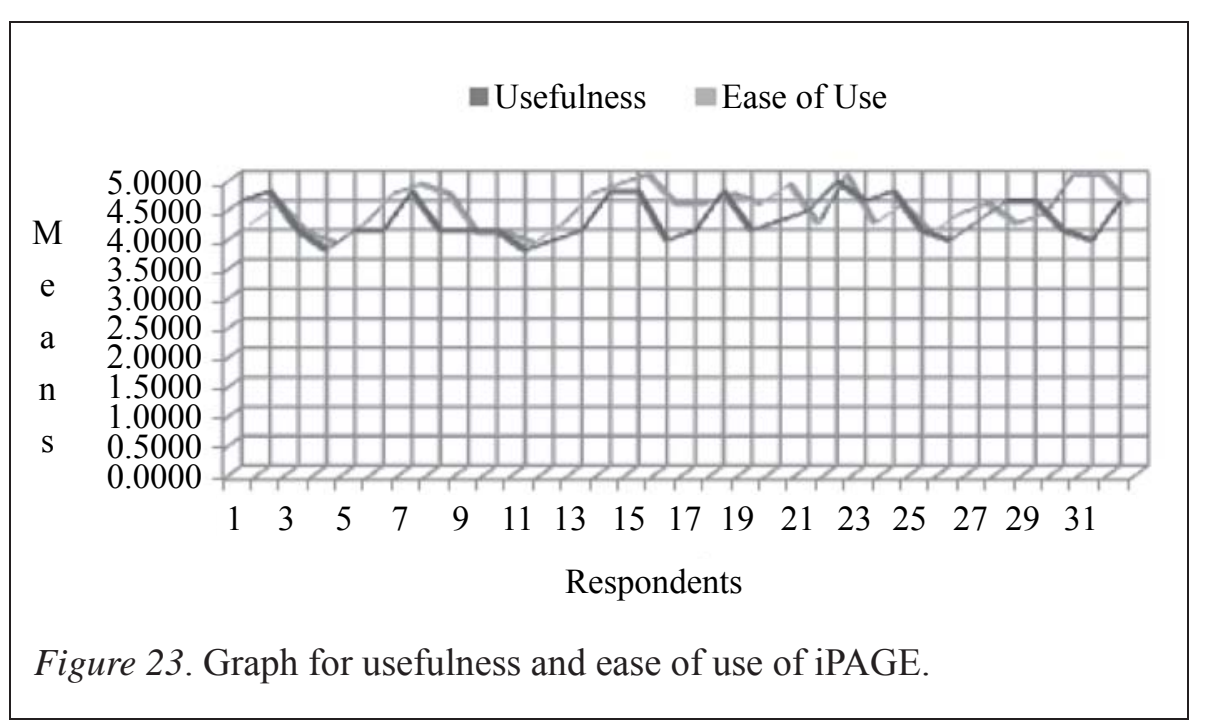

The validation process also involved DW experts and specialists in the field of the graduate entrepreneurship domain. Comments and suggestions from these experts show that the iPAGE BI application's feature is required to facilitate the integration of business information and entrepreneur reporting. This helps the MOHE management to plan and implement the graduate entrepreneur programme in Malaysia. In the requirements analysis, the experts stated three important issues to be considered in the development of the iPAGE. These issues are: (a) the application requirements should take into account the target iPAGE organizations such as vision, mission and key objectives of the organization; (b) the DW data model should be flexible to new requirements present in the organization; and (c) the requirement analysis for BI applications should involve participation from all communities, and it can be done manually or through online collaboration. Moreover, the experts agreed that entrepreneurship information from iPAGE can be used as a key reference point among graduate business management at MOHE, public and private IHLs, and MAKMUM. 


\section{CONCLUSION}

The web entrepreneur profile and web entrepreneur portal have been successfully implemented in a real environment. Both were incorporated in the iPAGE system that complements the concept of the operational system and the BI in an information system. The provided information is directly accessible to users through several stages of portal facilities. Various styles of reporting have been used to support MOHE for developing the entrepreneurship policy in a more systematic and holistic manner. Moreover, testing and the evaluation system have shown that iPAGE can be used to implement the BI in the entrepreneur system. However, user feedback is also important to ensure conformity with the requirements analysis and reporting of the information required. This has been proven in the iPAGE validation and evaluation processes. It is hoped that the iPAGE can be used to be a benchmark for the development of a comprehensive integrated entrepreneur information system in the future.

\section{REFERENCES}

Abu Bakar, M. S., \& Shiratuddin, N. (2009). Community and data integration approach using ReCODS model for business Intelligence Application. In 3rd International Conference on Communication and Information Technology (CIT'09), Athens.

Baragoin, C., Marini, M., Morgan, C., Mueller, O., Perkins, A., \& Yim, K. H. (2001). Building the operational data store on DB2 UDB using IBM data replication, websphere MQ family, and DB2 warehouse manager. San Jose, California: IBM Corporation.

Barney, J. (1991). Firm resources and sustained competitive advantages. Journal of Management, 17, 99-120.

Bento, A., \& Bento, R. (2006). Factors affecting the outcomes of performance management systems. Journal of Information Technology Management, XVIII (2), 23-32.

Borysowich, C. (2007). Prototyping: Types of prototypes [Electronic Version]. Enterprise implementation issues \& solutions. Retrived from http:// it.toolbox.com

Broadbent, M., \& Weill, P. (1993). Improving business and information strategy alignment: Learning from the banking industry. IBM System Journal, 32 (1), 162-179.

Date, C. J. (2007). An introduction to database systems (8th ed.). Reading, MA: Addison Wesley. 
Davis, F. D. (1989) Perceived usefulness, perceived ease of use, and user acceptance of information technology. MIS Quarterly, 13(3), 319-340.

Erickson, A. (2005, 19-20 May). Industries drivers \& best practice for business intelligence. Paper presented at the EUCI's Business Intelligence for Utilities - 2nd Annual Conference, Chicago, Illinois.

Filzah, et al. (2009). Kajian pengesanan bekas peserta kursus asas keusahawanan siswazah (KAKS): Kes UUM. Seminar Kebangsaan Hasil Penyelidikan Pembangunan Usahawan. Shah Alam.

Galbraith, J. R. (1973). Designing complex organizations. Reading, MA: Addison-Wesley.

Gartner. (2010). Gartner reveals five business intelligence predictions for 2009 and beyond. Retrieved from http://www.gartner.com

Gibson, M., Arnott, D., \& Jagielska, I. (2004, 1 to 3 July). Evaluating the intangible benefits of business intelligence: Review \& research agenda. Paper presented at the Proceedings of the 2004 IFIP International Conference on Decision Support Systems (DSS2004): Decision Support in an Uncertain and Complex World, Prato, Italy.

Grant, R. M. (1996). Towards a knowledge-based theory of the firm. Strategic Management Journal, 17(Winter Special Issue), 109-122.

Imhoff, C., Galemmo, N., \& Geiger, J. G. (2003). Mastering data warehouse design: Relational and dimensional techniques. Indianapolis, Indiana: Wiley Publishing.

Inmon, W. H. (1999). Building the operational data store (2nd ed.). John Wiley \& Sons.

Inmon, W. H. (2000, January). ODS types. DM Review Magazine.

Kimball, R., \& Caserta, J. (2004). The data warehouse ETL toolkit. Practical techniques for extracting, cleaning, conforming and delivering data. Indianapolis: Wiley.

Kimball, R., \& Ross, M. (2002). The data warehouse toolkit: The complete guide to dimensional modeling (2nd ed.). John Wiley \& Sons.

Kirby (1992). Developing graduate entrepreneurs: The UK graduate enterprise program. Entrepreneurship, Innovation and Change, 1(2), 165-177.

Mannino, M. V. (2007). Database design, application development, and administration. Irwin: McGraw-Hill.

Mohanty, S. (2006). Data warehousing design, development and best practices. Tata McGraw-Hill.

MOHE (2010). Dokumen Dasar Pembangunan Usahawan IPT.

Negash, S., \& Gray, P. (2003, August 4-6). Business Intelligence. Paper presented at the Ninth Americas Conference on Information System (AMCIS 2003), Tampa, Florida. 
Olszak, C. M., \& Ziemba, E. (2006). Business Intelligence Systems in the holistic infrastructure development supporting decision-making in organisations. Interdisciplinary Journal of Information, Knowledge, and Management (IJIKM), 1, 47-58.

Rainer, R. K., Turban, E., \& Potter, R. E. (2007). Introduction to information system : Supporting and transforming business. John Wiley \& Sons.

Rasmussen, N., Goldy, P. S., \& Solli, P. O. (2002). Financial business intelligence: Trends, technology, software selection, and implementation. John Wiley \& Sons.

Reinschmidt, J., \& Francoise, A. (2000). Business intelligence certification guide (1st ed.). San Jose, California: IBM Corporation.

Rofail, G. (2005, May 19-20). Business intelligence for specific business applications-customize the right data for marketing business intelligence. Paper presented at the EUCI's Business Intelligence for Utilities - 2nd Annual Conference, Chicago Illinois.

Taa, A., Abdullah, M. S., \& Norwawi, N. M. (2011). Goal-Ontology ETL Processes Specification. Journal of Information and Communication Technology, 10, 15-43.

Tatikonda, M. V., \& Rosenthal, S. R. (2000). Technology novelty, project complexity, and product development project execution success: A deeper look at task uncertainty in product innovation. IEEE Transactions on Engineering Management, 47 (1), 74-87.

Venkatesh, V., \& Davis, F. D. (2000). A theoretical extension of the technology acceptance model: Four longitudinal field studies. Management Science, 46(2), 186-204.

$\mathrm{Wu}$, J. (2000). What is business intelligence? Retrieved from http://www. dmreview.com

Yahya, M. A., Mohd Yusof, S. A., \& Abu Bakar, M. S. (2009). Model integrasi pembangunan usahawan siswazah. Dalam Seminar Kebangsaan Hasil Penyelidikan Pembangunan Usahawan, Shah Alam. 